\title{
International Conference on the Nanotechnology 'NanoIsrael 2009” (Jerusalem, Israel, March 30-31, 2009)
}

\author{
DOI: $10.1134 / \mathrm{S} 1023193509110184$
}

This representative conference mustered several hundreds of participants from 29 countries, mainly from Israel. Its purpose was bringing together chemists, physicists, biologist, and engineers working on the nanotechnology. The great deal of presented papers was devoted to fundamental research; nevertheless, the conference obviously had a propensity for applications: many papers was dedicated to commercialization of basic results, which can be well seen from their titles: "Nanotech Commercialization: Past, Present, Future" by M. Nordan (USA), "European Nanotechnology Strategy" by H. von Bosé (Belgium), "Nanotechnology, Managing a High-Tech Company in Turbulence" by Z. Yaniv (USA). The chief idea of these papers is that in the high-tech (in particular, nanotechnology) research the human factor, that is, high-level skill and creativity appeared more important than even financing. In the field of power engineering the increase in the effectiveness of energy using is more important then the increase in the power production. The program of the conference also included presentation and the exhibition of companies working in the market of the nanotechnology.

The scientific program consisted of 49 plenary lectures and oral presentation and 220 posters. They can be grouped as follows: energy production and environment (solar energy, lithium-ion batteries), nanomaterials (production and properties), nanoelectronics and nanophotonics, nanobiosensing and nanomedicine. The following works are related directly to electrochemistry.

Lithium-ion batteries. The greater part of these works dealt with a new electrode material, namely, silicon. It is known that silicon can be intercalated by lithium an order heavier $(4200 \mathrm{~mA} \mathrm{~h} / \mathrm{g})$ than traditional carbonaceous anodes. However, this advantage turns to a disadvantage: upon the intercalation, the silicon volume increases drastically, its structure fails; as a consequence, the electrode demonstrates very poor cycleability. Y. Cui (USA) suggested using the silicon electrode in the form of Si-nanotubes, rather than solid film, because the nanotube structure does not disintegrate upon the intercalation-deintercalation cycles; as a result, high reversible capacitance was achieved (ten times higher than that of carbon electrodes), as well as good cycleability (after 185 cycles, the capacitance decreased no more than by 5\%). A variant of the anode material is a system of core-shell nanorods perpendicular to the substrate. The nanorod core is made of crystalline silicon; the shell, of amorphous silicon (which is just the inserted lithium reservoir). We note that the Si- nanotubes can be used in the producing supercapacitors whose capacitance exceeds that of traditional carbonaceous supercapacitors by order of magnitude. This work is adjoined by that of D. Golodnitsky (Israel) who used perforated silicon anode $\left(25000\right.$ holes per $\left.1 \mathrm{~cm}^{2}\right)$ on which $\mathrm{V}_{2} \mathrm{O}_{5}, \mathrm{FeO}_{x} \mathrm{~S}_{2-x}$, and $\mathrm{Cu}_{2} \mathrm{O}$ nanocomposites are deposited ( $\mathrm{Li}$ is inserted to these very nanocomposites). Here each microchannel works as a concentric microbattery; in aggregate, they represented a three-dimensional (3D) battery.

Solar energy conversion. A.P. Alivisatos (USA) overviewed the state-of-art of this renewable energy source. N.S. Sariciftci (Austria) discussed processes of preparation of synthetic fuels in cells containing organic and inorganic structures based on conjugate polymers and fullerenes. Great attention of the conferees was attracted to photoelectrochemical cells containing nanocrystalline semiconductor photoanode (usually $\mathrm{TiO}_{2}$ ) sensitized to sunlight using a dye with the corresponding absorption spectrum and either liquid redox electrolyte or solid polymer electrolyte (G. Frey, Israel). Another object of interest was electrolyte-free solar cell for photoelectric solar energy conversion to electric energy. A. Zaban (Israel) described a cell with $\mathrm{I} / \mathrm{I}_{3}^{-}$electrolyte filled with semiconductor particles of the core-shell type, in which the core and the shell were made of semiconductors with different band gap; this approach allowed using the sunlight energy more effectively. He also suggested arranging the solar cells along a waveguide through which solar light propagated; thus the effect of multiple total internal reflection can be used for more effective light absorption, hence, higher conversion efficiency. Similar effect was analyzed by S. Greenwald (Israel) in a poster. Organic dye-sensitizers can be replaced by sunlight-absorbing metal oxides, in particular, $\mathrm{CdS}, \mathrm{Cu}_{2-x} \mathrm{~S}, \mathrm{CdSe}, \mathrm{CeO}_{2}$ (O. Niitsoo, I. Hod, both from Israel).

Nanomaterials. The main part of works presented in the conference was devoted to the preparation and studying of different nanomaterials. R. Tenne (Israel) in his plenary lecture discussed methods of preparing nanotubes made of $\mathrm{WS}_{2}$ and $\mathrm{MoS}_{2}$. V. Hilarius (Germany) described methods of chemical deposition of nanoparticles whose core is coated by functional layers. Two papers were devoted to nanocrystalline diamond (V. Dolmatov, Yu.V. Pleskov, both from Russia).

Yu. V. Pleskov 